\title{
ECC
}

Eurasian Chemical Communications

\section{Use of data mining in the corrosion classification of pipelines in catalytic reforming units (CRU)}

\author{
Amir Samimia, Soroush Zarinabadib,*, Amir Hossein Shahbazi Kotanaeia, \\ Alireza Azimia , Masoumeh Mirzaeia \\ a Department of Chemical Engineering, Mahshahr Branch, Islamic Azad University, Mahshahr, Iran \\ ${ }^{b}$ Department of Engineering, Ahvaz Branch, Islamic Azad University, Ahvaz, Iran
}

Received: 10 May 2019, Accepted: 16 June 2019, Published: 1 November 2019

\begin{abstract}
Nowadays, computational tools for analyzing and collecting data in the operation of petroleum units are essential. One of the methods is the classification or regression is to step in the overall process of knowledge extraction. In this study, one of specific type of decision called the conditional contract arrangement, is used to extract the relevant knowledge in Catalytic Reforming Units (CRU) for 4 factors: Density, PH, total iron ions in vessels (S.FE) and $\mathrm{H}_{2} \mathrm{~S}$. All of these factors are related to corrosion in CRU and this paper aims to optimize some conditions to eliminate it. In this regard, using ammonium water with a specific range and $\mathrm{PH}$ can be helpful. According to the obtained results the best range of density (in Feed) is less than $0.515 \mathrm{~kg} / \mathrm{m}^{3}, \mathrm{PH}$ (water in vessels) is more than 6.7, S.FE is less than $1.5 \mathrm{ppm}$ and $\mathrm{H}_{2} \mathrm{~S}$ in recycle gas is less than $700 \mathrm{ppm}$. The outcomes also show how this approach can be used to gain insight into some refineries and how to deliver results in a comprehensible and user-friendly way.
\end{abstract}

Keywords: Ammonium water; corrosion; tree decision algorithm; catalytic reforming unit; computational tools.

\section{Introduction}

At the outset of the millennium, the amount of data generated and cataloged by monitoring systems such as Distributed Control System (DCS) is increasing. In many cases, especially in petrochemical and Refinery companies, all of data contained in the DCS can provide into the underlying physical processes [1]. In a nutshell, the decision tree is a map of probable outcomes of a range of choices or related options that allow an individual or organization to measure probable measures in terms of costs, probabilities, and benefits. The decision tree can be used either to advance personal and informal goals or plans, or to draw up an algorithm that predicts the best option based on mathematics [2]. A decision tree usually starts with an initial node, after which potential consequences are branched out, and each of those consequences leads to other nodes, which in turn create branches of other probabilities that this branching structure eventually turns into a tree-like graph. In the decision tree, there are three types of nodes (nodes) that are: 
- Random Nodes

-Decision Nodes

$\bullet$ End nodes

The random ninth represented by a circle indicates the likelihood of occurrence of a particular result, the decision node, represented by a square, shows the decision that can be made, and the final ninth represents the final outcome of a decision path [3]. Decision trees can also be drawn with symbols or flowchart signs, which will make it easier for some people, to understand and understand it (Figures 1 and 2).

Xiaoyong G., (2018) shows [4] petrochemical companies and universities during these days. Due to this article to the petrochemical complexes of industries some informations have been reported for better use in all of the world. They have also proposed new way to exploit the prior knowledge existing in industries, and increased a new decision making system to help the scheduling process.
Alexis Sarda Spinoza et al., in an article using a specific type of tree decision algorithm, called the bet order, to extract relevant knowledge from data related to electric motors and analyze them. The Suitable method for these information is evaluated as well as others [5].

Marton, I., et al., (2013), in another paper on RAP refinement asphalt, used the decision tree algorithm to analyze the available data. The results indicate that choosing a balanced mix design is dependent on the selection of appropriate levels of RAP content and binding rating to the application conditions in terms of temperature and loading density [6].

Mazloumi, E., et al., (2011), Using the C-Tree software, which is a nonparametric class of regression trees, well describes regression organisms in a theory, the Conditional Inference Method examines existing problems. This applies to all types of regression, including nominal, row, numeric, and censored variables, as well as several variables and arbitrary scale measurements of private [7].

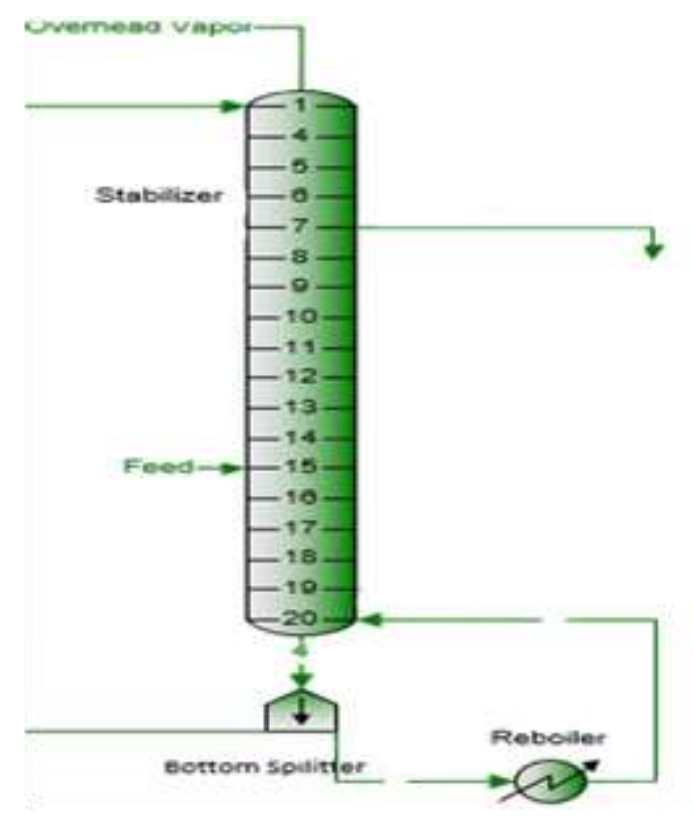

Figure 1. Stabilizer Shematic 


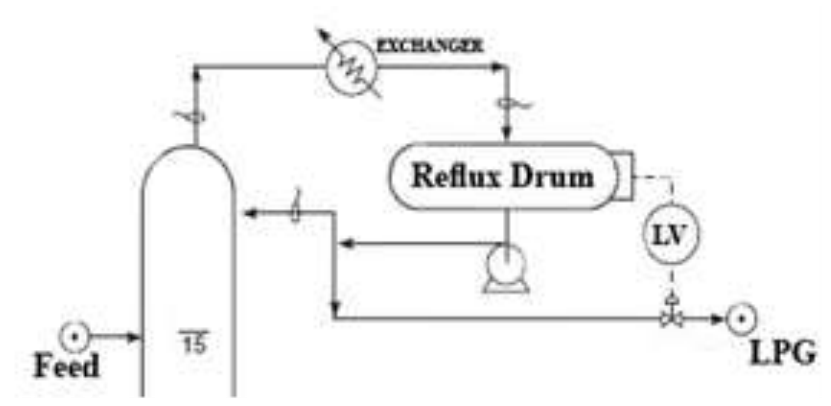

Figure 2. Reflux Drum Shematic-

Data collection and classification

Data collection and storage technologies have made it possible for organizations to extract a large amount of data in the shortest possible time. The exploitation of this stored data, in order to extract useful and practical information, is the general purpose of the public activity known as data mining. Data mining the process of discovery and analysis, either automatically or semi-automatic, is of greatly high value in order to discover meaningful patterns and rules [8,9]. Data mining is an interdisciplinary branch of computer science that involves the discovery of patterns from a large set of data. The purpose of this advanced analysis process is to extract information from a dataset and turn it into an understandable structure for later use. The methods used are a combination of artificial intelligence, machine learning, statistics, and database systems and business intelligence [10,11]. In CRU density should be less than $0.515, \mathrm{H}_{2} \mathrm{~S}$ in recycle gas must be less than 700 . $\mathrm{PH}$ in separator and reflux drum is limited. This means that if $\mathrm{PH}$ is less than 5 , it is inappropriate and shows the high corrosion (HC) in pipelines, if $\mathrm{PH}$ between 5 to 6.7 , it means that data is suitable and good. In this case we have low corrosion (LC) in pipelines. If $\mathrm{PH}$ more than 6.7, although it means that data is optimum and suitable, without any corrosion, injection of chemical materials is more than enough and companies must pay dollars excess. S.FE means Iron which is corrosive in the pipeline. Normally S.FE must less than 2 ppm in separator drum and 0.5 in reflux drum. In Table 1, the data definition for analyzing PH is explained. This can be a challenging issue because imputing the values is not a straightforward homework. In Table 2, the data definition for analyzing S.FE is explained. These data are also challenging issue. In Table 3 , the data definition for analyzing $\mathrm{H}_{2} \mathrm{~S}$ in recycle gas. This table shows the appropriate and inappropriate data. Established: They use well-known, established statistical concepts for variable selection and stopping. The resulting tree models are easier to communicate with practitioners (Figures 3 and 4).

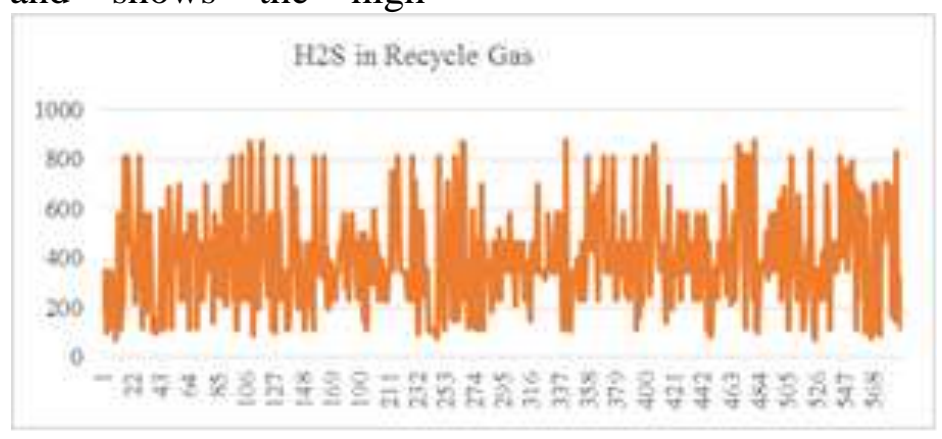

Figure 3. $\mathrm{H}_{2} \mathrm{~S}$ in Recycle Gas in CRU 


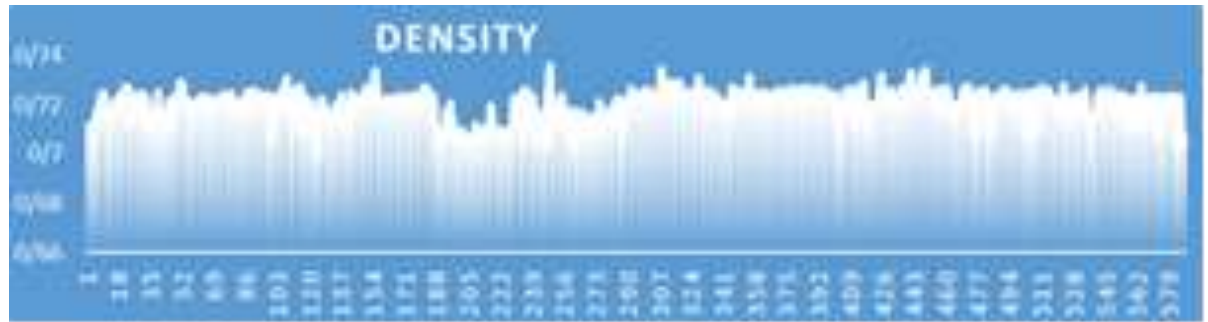

Figure 4. Feed density in CRU

Table 1. Data Definition for Analyzing PH

\begin{tabular}{ccc}
\hline High Corrosion (HC) & Low Corrosion (LC) & Optimum Data (OD) \\
\hline $5<\mathrm{PH}$ & $5<\mathrm{PH}<6.7$ & $6.7>\mathrm{PH}$ \\
\hline
\end{tabular}

Table 2. Data Definition for Analyzing S.FE

\begin{tabular}{cccc}
\hline \multicolumn{2}{c}{ Separation Drum } & \multicolumn{2}{c}{ Reflux Drum } \\
\hline $\begin{array}{c}\text { Number of data } \\
\text { which are Less } \\
\text { than 2 ppm }\end{array}$ & $\begin{array}{c}\text { Number of data } \\
\text { which are More } \\
\text { than 2 ppm }\end{array}$ & $\begin{array}{c}\text { Number of data } \\
\text { which are Less } \\
\text { than } 0.5 \mathrm{ppm}\end{array}$ & $\begin{array}{c}\text { Number of data } \\
\text { which are More } \\
\text { than } 0.5 \mathrm{ppm}\end{array}$ \\
\hline 509 & 81 & 498 & 92 \\
\hline
\end{tabular}

Table 3. Data Definition for Analyzing $\mathrm{H}_{2} \mathrm{~S}$ $\mathrm{H}_{2} \mathrm{~S}$ in Recycle Gas in CRU

Number of data which are Less than 700 (ppm) Number of data which are More than 700 (ppm) 508 178

Table 4. Data Definition for Analyzing Density

\section{Stabilizer Section}

\section{Reflux Drum}

\begin{tabular}{lccc}
\hline $\begin{array}{l}\text { Number of data which } \\
\text { are Less than } 0.515\end{array}$ & $\begin{array}{c}\text { Number of data which } \\
\text { are More than } 0.515\end{array}$ & $\begin{array}{c}\text { Number of data which } \\
\text { are Less than } 0.515\end{array}$ & $\begin{array}{c}\text { Number of data which } \\
\text { are More than } 0.515 \\
\mathrm{~kg} / \mathrm{m}^{3}\end{array}$ \\
$\mathrm{~kg} / \mathrm{m}^{3}$ & 60 & $\mathrm{~kg} / \mathrm{m}^{3}$ & 78 \\
\hline
\end{tabular}

Table 5. Temperature and Pressure in Stabilizer in normal condition

$\begin{array}{cc}\text { Temperature and Pressure in Stabilizer Over Head } \\ \text { Temperature (SOR) }{ }^{\circ} \mathrm{C} & \text { Pressure (SOR) Bar } \\ 50 & 15.5 \\ \text { Temperature (EOR) }{ }^{\circ} \mathrm{C} & \text { Pressure (EOR) Bar } \\ 65 & 13\end{array}$

SOR: Start Of Run

Eor: End Of Run

\section{Process of catalytic reforming unit (CRU)}

The goal of the Catalytic Reforming (CRU) Unit is to produce clean and refined feed for the supply of Octane and Isomerization units [12]. The feeds of these units should have the lowest amount of pollutants such as sulphur, nitrogen, water, halogens, diolefins, olefins, arsenic, mercury and other metals, so that the efficiency of the lower units, especially the catalyst, is not affected by these units $[13,14]$.

All of these cuts can have different levels of super-pollution, which is catalytic converting and isomerization catalytic converters, and therefore hydrogen refining operations are 
essential $[15,16]$. The process of CRU is carried out in a reactor in the presence of a nickel-molybdenum bimetallic catalyst and in the presence of hydrogen (Tables 4 and 5).

The temperature is relatively high (about $270{ }^{\circ} \mathrm{C}$, the temperature should be more than $250{ }^{\circ} \mathrm{C}$ which reaction would be started) required for the process to be performed. After chemical reactions, naphtha is subjected to buckling operations to separate hydrocarbon and gas components including hydrogen sulphides $\mathrm{H}_{2} \mathrm{~S}$ and water [17].

Then, the oil cut in the separating tower (Splitter tower) is divided into two distinct sections for feeding the isomerization unit (Light Naphtha) and the Octanizer unit (Heavy Naphtha). Surprisingly the high efficiency of the octane units and isomerization depends greatly on the efficiency and efficiency of the naphtha purification unit $[18,19]$. The maximum limit for sulphur and nitrogen contamination in the refined feed unit is $0.5 \mathrm{ppm}$ and the final limit of contamination such as lead, copper, silica, nickel, chromium is less than ppb 10.

\section{LPG recovery and stabilization saction}

The separated liquid from recontacting drum is contacted with stabilizer off-gas and allowed to separate in the LPG Absorber Drum. The purpose of this step is to recover the maximum quantity of LPG, i.e. C3 and C4's from the stabilizer overhead. Vapor from LPG Absorber Drum is sent to fuel gas. This stream is predominantly light ends i.e. $\mathrm{C} 1$ and C2's and this controls the stabilizer operating pressure [20-23]. Separated liquid from LPG Absorber Drum is pumped by LPG Absorber Bottom Pumps, under flow control with level reset and is sent through the stabilizer feed/bottom exchanger to the Stabilizer Feed Chloride Adsorbers (in order to remove all traces of chlorides) and finally through the stabilizer feed/bottom exchanger to enter the stabilizer column Reflux Drum on tray 15.

Note that a back pressure is maintained on the stabilizer feed chloride adsorbers to ensure no vaporization occurs with the stabilizer feed. The target operating temperature for chloride removal is approximately $100{ }^{\circ} \mathrm{C}$. The stabilizer operating at 15.5 bar $\mathrm{g}$ at the top allows reducing the $\mathrm{C} 4$ fraction in the reformate to less than $1.0 \mathrm{vol} . \%$ and the $\mathrm{C}+$ fraction in the LPG to less than $0.5 \%$ wt. The stabilizer is reboiled with a fired reboiler, circulating with Stabilizer Reboiler Pumps. Temperature control is on trays 7 and 20. Reflux Drum Stabilizer overhead is partially condensed in exchanger Stabilizer Air Condenser and in exchanger Stabilizer Trim Condenser, to collect in Stabilizer Reflux Drum. The reflux drum overhead vapor is routed back to LPG absorber drum for LPG recovery [24-26]. A part of the separated liquid is pumped Stabilizer Reflux Pumps, under flow control with temperature reset back to reflux drum as reflux. The remaining part of the separated liquid is routed to the battery limits [27].

Reformate from the bottom of the stabilizer is cooled in the Stabilizer Feed/Bottom Exchangers, and further cooled down in exchanger Reformate Air Cooler and exchanger Reformate Trim Cooler before being sent to storage.

\section{Problem statement}

The presence of sulphur is accompanied by increased corrosion in the operating units, and one of the ways to solve this problem of corrosion and its reduction is to use ammonia water[28-29].

\section{Chemical control method for CWT: Combined water treatment}

The method (CWT) is in fact a mixture of the two previous methods. This 
method is used to prevent problems in chemical control (NWT) and (AVT) methods. In this method, by adding ammonia to feed water, the $\mathrm{pH}$ is introduced in the range of 8.5 to 8 and the injection of oxygen into the system, like the method (NWT) Here are some of the benefits of the CWT method:

1. Changing the protective iron oxide layer $\left(\mathrm{Fe}_{3} \mathrm{O}_{4}\right)$ to the hematite protecting layer $\left(\mathrm{Fe}_{3} \mathrm{O}_{3}\right)$ and reducing the dissolution rate of iron. According to the formula and the following form: The formation of a magnetic oxide layer in the AVT regimen in the absence of oxygen Formation of the hematite layer $\left(\mathrm{Fe}_{3} \mathrm{O}_{3}\right)$ in CWT with oxygen [30-31].

2. Reducing the cost of chemicals: Because hydrazine and phosphate are not used in this method and ammonia is used a little, it reduces the cost of chemicals [32].

3. Lack of Coarse Layer: In CWT method, due to the formation of a uniform hematite layer, corrugated layers do not form in the inner surfaces of the pipes, which reduces the flow resistance of the flow of water and ultimately saves electrical power, because in the AVT method The reason for the formation of corrugated layers to achieve a specific pressure (P2) is greater pressure than the CWT method.

4. Environment: In CWT, removal of hydrazine and phosphate and low ammonia consumption have less pollutant content in the industrial effluent.

In this study we show that we can use conditional inference trees to analyze our data to decrease and solve corrosion in the unit [33].

\section{Experimental section}

Data collection and storage technologies have made it possible for organizations to extract a large amount of data in the shortest possible time. The exploitation of this stored data, in order to extract useful and practical information, is the general purpose of the public activity known as data mining. Data mining the process of discovery and analysis, either automatically or semi-automatic, is of greatly high value in order to discover meaningful patterns and rules. Data mining is an interdisciplinary branch of computer science that involves the discovery of patterns from a large set of data.

The purpose of this advanced analysis process is to extract information from a dataset and turn it into an understandable structure for later use. The methods used are a combination of artificial intelligence, machine learning, statistics, and database systems and business intelligence.

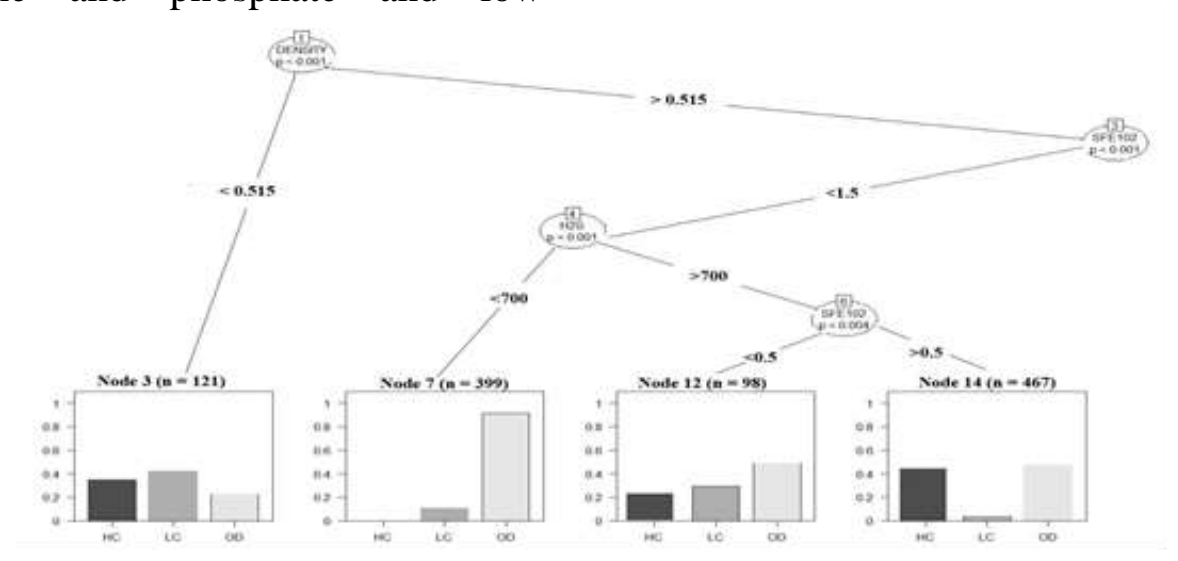

Figure 5. The results of data for Stabilizer in CRU. (Node 3,7,12 and 14) 


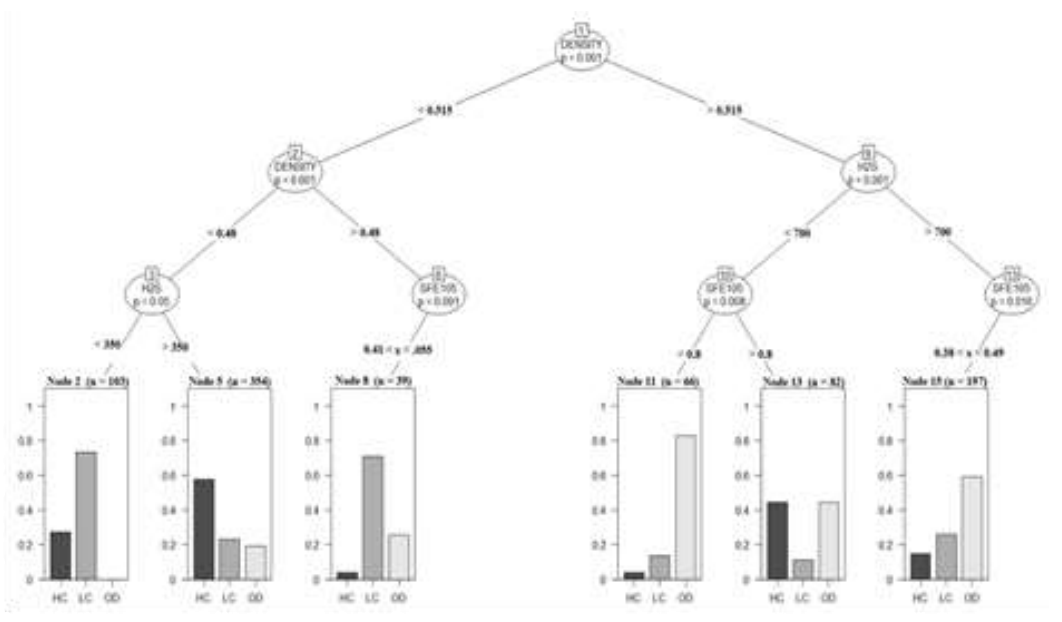

Figure 6. The results of data for Stabilizer in CRU. (Node 2, 5, 8, 11, 13 and 15)

\section{Methodology for analysis}

\section{Part A: Separator Drum}

According to Figure 5, it is observed that:

1. When the density is less than or equal to 0.515 , according to the amount of data available in these conditions (121 cases), all three states have seen (Node 3):

A: High corrosion rate is approximately $30 \%$

B: Low corrosion rate is more than $45 \%$,

C: Percentage of optimum is approximately 25

2. When the density of more than 0.515 , the amount of iron in the samples is less or equal than $1.5 \mathrm{ppm}$ and the amount of $\mathrm{H}_{2} \mathrm{~S}$ in the compressor gas is less or equal than to $700 \mathrm{ppm}$, according to the amount of data available in these conditions (399 cases, The most available data, given the operating conditions of the unit over time), it can be said that only two states have seen (Node 7):

A: Low corrosion rate is less than $9 \%$,

$\mathrm{B}$ : Percentage of optimum is approximately $91 \%$

3 . When the density value is greater than 0.515 , the iron content in the samples is less or equal than to $1.5 \mathrm{ppm}$, and the $\mathrm{H}_{2} \mathrm{~S}$ content of the compressor gas is greater than $700 \mathrm{ppm}$, the iron content according to the smaller selectable range for the amount of iron for better analysis The results, in these conditions ( 98 cases, when the iron content is less than $0.5 \mathrm{ppm}$ and 467 cases when the iron content is greater than $0.5 \mathrm{ppm})$, only two states have seen (Node 12 and 8):

\section{Node 12:}

A: High corrosion rate is approximately $24 \%$

B: Low corrosion rate is approximately $31 \%$,

$\mathrm{C}$ : Percentage of optimum is approximately 45

Node 14:

A: High corrosion rate is approximately $45 \%$

$\mathrm{B}$ : Low corrosion rate is approximately 5\%,

$\mathrm{C}$ : Percentage of optimum is approximately 50

\section{Part B: Reflux drum}

According to Figure 6, it is observed that:

1. When the density value is less or equal than 0.515 , even though the density more or equal than 0.48 , if $\mathrm{H}_{2} \mathrm{~S}$ content of the compressor (recycle) gas is less or equal than 350 ppm,(103 cases), only two states have seen (Node 2):

A: High corrosion rate is approximately $28 \%$ 
B: Low corrosion rate is approximately $72 \%$,

And if $\mathrm{H}_{2} \mathrm{~S}$ content of the compressor (recycle) gas is greater than 350 ppm,(354 cases), three states have seen (Node 5):

A: High corrosion rate is approximately $59 \%$

$\mathrm{B}$ : Low corrosion rate is approximately $23 \%$,

C: Percentage of optimum is approximately 18

2 . When the density value is less or equal than 0.515 , even though the density less than 0.48 , if SFE content is less or equal than $0.55 \mathrm{ppm}$ and greater than $0.41 \mathrm{ppm}$, (39 cases), three states have seen (Node 8):

A: High corrosion rate is less than $6 \%$

$\mathrm{B}$ : Low corrosion rate is more than $66 \%$,

$\mathrm{C}$ : Percentage of optimum is approximately 28

3 . When the density value is more than 0.515 , the $\mathrm{H}_{2} \mathrm{~S}$ content of the compressor (recycle) gas is less or equal than $700 \mathrm{ppm}$, if SFE content is less or equal than $0.8 \mathrm{ppm},(66$ cases $)$, three states have seen (Node 11):

A: High corrosion rate is less than 7\%

$\mathrm{B}$ : Low corrosion rate is approximately $14 \%$,

$\mathrm{C}$ : Percentage of optimum is approximately 79

And if SFE content is greater than 0.8 ppm,(82 cases), three states have seen (Node 13):

A: High corrosion rate is more than $45 \%$

B: Low corrosion rate is more than $13 \%$

$\mathrm{C}$ : Percentage of optimum is approximately 42

4. When the density value is more than 0.515 , the $\mathrm{H}_{2} \mathrm{~S}$ content of the compressor (recycle) gas is more than $700 \mathrm{ppm}$, if SFE content is less or equal than $0.49 \mathrm{ppm}$, and more than $0.38 \mathrm{ppm}$ (197 cases), three states have seen (Node 15):

A: High corrosion rate is less than $16 \%$
$\mathrm{B}$ : Low corrosion rate is is approximately $23 \%$,

$\mathrm{C}$ : Percentage of optimum is approximately 62

As this chart shows, $\mathrm{H}_{2} \mathrm{~S}$ is very variable. These data are between 62 to $872 \mathrm{ppm}$. In manual, licensors told that $\mathrm{H}_{2} \mathrm{~S}$ should be more than $150 \mathrm{ppm}$. It is because of catalyst in the reactor. As this chart shows, $\mathrm{PH}$ is approximately fixed. These data are between 0.7 to 0.74 , in manual licensors told that feed density in the unit should be neither more than 0.69 nor more than 0.74 .

\section{Conclusion}

The duty of the unit is to produce reformate with high octane with high purity hydrogen. The design, operation and control strategies of the unit are such as to maximize the production of the valuable high octane reformate stream and to ensure consistent quality of the rich hydrogen gas as this may impact on the performance of the upstream and downstream hydrogen users. In the present study, the data come from an Oil Refinery Company, but in practical terms, the general methodology presented in this work can be applied to many other situations such as refineries and petrochemical companies. Also the number of available ML algorithms is staggering, clearly, the first choice to be made is which algorithms are going to be tested, and something that depends heavily on the scope, and is not always straightforward since no single algorithm can perform optimally in every situation. The purpose of the predictive model is to allow the data explorer to predict an unknown value (often occurring in the future) from a specific variable. If the value to be found is one of the predefined class members, this type of data mining is called Classification. If the target variable has a real value, data mining is a regression type. 
For Separator drum (data for separator vessel in CRU), the optimal mode is Node 7. In this case, the highest optimum (best condition) is visible. Most of the samples are taken in this state, which shows the effectiveness of the effect of ammonia water injection into the system.

For Reflux Drum (data of Reflux for Stripper vessel in CRU), the optimal mode is No. 8 or Node 11. In this case, the highest optimum (best condition) is visible. Most of the samples are taken in this state, which shows the effectiveness of the effect of ammonia water injection into the system for Reflux of Stripper vessel in CRU.

Finally, our results show how this approach can be used to gain insight into some refineries, deliver results in a comprehensible and user-friendly way.

\section{Acknowledgements}

The work presented in this paper is part of a research project of Amir Samimi (Ph.D. student in science in chemical engineering, Department of Chemical Engineering, Mahshahr Branch, Islamic Azad University, Mahshahr, Iran).

\section{References}

[1] S. Arlot, A. Celisse, Stat. Surv., 2010, 4, 40-79.

[2] L. Ting L., Z. Yuannong, J. Chunhua, Y. Guobin, Z. Zhengyu, Journal of Atmospheric and Solar-Terrestrial Physics, 2018, 179, 389-395.

[3] A. Nahla Ben, E. Zeineb, F. Hélène, S. Sabbadin, Fuzzy Sets and Systems, 2018, 99-104.

[4] K. Khalili-Da., F. Abdi, S. Aboni., Applied Soft Computing, 2018, 73, 816828.

[5] M. Gerdes, Master's thesis. Linköping University, Fluid and Mechatronic Systems, the Institute of Technology, 2017, 11-42.

[6] T. Hastie, R. Tibshirani, J. Friedman, Springer, 2009, 15, 587-604.
[7] W. Lihong., L. Qiang., Y. Yanwei., L. Jinglei., Expert Systems with Applications, 2018, 105, 112-128.

[8] S. Janitza., G. Tutz., A. Boulesteix., Comput. Stat. Data Anal., 2016, 57-73.

[9] GU. Shankru., K. Vijayakumar., V. Umadevi, Future Computing and Informatics Journal, 2018, 210-224.

[10] G. Xiaoyong., H. Dexian., J. Yongheng., T. Chen., Chinese Journal of Chemical Engineering, 2018, 26, 16051612.

[11] I. Marton., A. Sánchezb., S. Carlosa., S. Martorella., Chem. Eng. Trans, 2013, 2, 301-306.

[12] E. Mazloumi., G. Rose., G. Currie., S. Moridpour., Eng. Appl. Artif. Intell., 2011, 3, 534-542.

[13] (a) S. Mohammadi, A. Taheri, Z. Rezayati-zad, Prog. Chem. Biochem. Res., 2018, 1, 1-10; (b) S. Sajjadifar, Z. Arzehgar, A. Ghayuri, Journal of the Chinese Chemical Society, 2018, 65, 205-211.

[14] S. Aline., L. Eduardo., A. Felipe de A. Mello Pereira., Information Processing Letters, 2017, 127, 27-31.

[15] T. Varga., F. Szeifert., J. Abonyi., Eng. Appl. Artif. Intell., 2009, 569-578.

[16] T. Madhar., Journal of Safety Research, 2018, 66, 121-129.

[17] H. OH., W.S. SEO., Japan Journal of Nursing Science., 2012, 3, 110-121.

[18] G. Zhou., L. Wang., Transportation Research: Part C, 2012, 287-305.

[19] S. Sohn., J. Kim., Expert Systems with Applications, 2012, 39, 4007-4012.

[20] J. Choand., P.U. Kurup., Sensors \& Actuators B: Chemical, 2011, 160, 542548.

[21] G. Stanley., The National Academy of Sciences, 2006, 88, 145-154.

[22] M. Saidi., N. Mostoufi., R. Sotudeh., International Journal of Applied Engineering Research, 2011, 2 , 540-555.

[23] M. Gyngazova., A.V. Kravtsor., E.D. Ivanchina., M.R. Korolenko., D.D. 
Uvarkina.,Catalysis in Industry, 2010, 2, 117-128.

[24] H. Weifeng., S. Hongye., MU. Shengjing., CHU. Jian., Chinese Journal of Chemical Engineering, 2007, 15, 75 80.

[25] S. Raseev, Science and Technology, 2003, 111-124.

[26] T. Gueddar., D. Vivek., Computer \& Chemical Engineering, 2011, 385, 18381856.

[27] M.S. Gyngazova, N.V. Chekantsev, M.V. Korolenko, E.D. Ivanchina, A.V. Kravtsov, Catalysis in Industry, 2012, 4, 284-291.

[28] D. Iranshah, M. Karimi, S. Amiri, M. Jafari, R. Rafiei, M. Rahimpour, Chemical Engineering Research and Design, 2014, 9, 1704-1727.

[29] M.Z. Stijepovic, A.V. Ostojic, I. Milenkovic, P. Linke, Energy \& Fuel Journal, 2009, 23, 979-983.

[30] H. Arani, M. Shirvani, K. Safdarian, E. Dorostkar, Journal Chemical Engineering, 2009, 26, 723-732.

[31] R.E. Palmer, S.H. Kao, C. Tong, D.R. Shipman, Hydrocarbon Processing., 2008, 55-66.

[32] A. Anatolevich, S. Michailovich, Chemical Methodologies, 2019, 1, 1-14 [33] S. Houshmandynia, R.. Raked, F. Golbabaei, Chemical Methodologies, 2018, 4, 270-340.

[34] H. Shafiee, F. Mostaghni, K. Ejraei, Chemical Methodologies, 2018, 2, 83180.

[35] O. Ghasemi, N. Mehrdadi, M. Baghdadi, B. Aminzadeh, Iran. Chem. Commun., 2019, 4, 352-3674.

[36] G. Mansouri, M. Ghobadi, Iran. Chem. Commun., 2019, 4, 424-431.

[37] S.M. Habibi-Khorassani, M. Dehdab, M. Darijani, Iran. Chem. Commun., 2019, 4, 455-471.

[38] F. Fayyaz Jorshari, M. Rabbani, R. Rahimi, M. Rassa, Iran. Chem. Commun., 2019, 1, 53-62.
[39] R. Motamedi, F. Ebrahimi, G. Rezanejade Bardajee, Asian J. Green Chem., 2019, 3, 22-33.

[40] S. Sajjadifar, I. Amini, H. Jabbari, O. Pouralimardan, M.H. Fekri, K. Pal, Iran. Chem. Commun., 2019, 7, 191-199. [41] A. Hassankhani, Iran. Chem. Commun., 2019, 7, 248-256.

[42] H. Hasani, M.Irizeh, Asian J. Green Chem., 2018, 2, 85-95.

[43] L. Nagarapu, M. Baseeruddin, S. Apuri, S. Kantevari, Catal. Commun., 2007, 8, 1729-1734.

[44] J. Luo, Q. Zhang, Monatsh. Chem., 2011, 142, 923-930.

[45] W.-Q. Jiang, L.-T. An, J.-P. Zou, Chin. J. Chem., 2008, 26, 1697-1701.

[46] M. Lei, L. Ma, L. Hu, Tetrahedron Lett., 2009, 50, 6393-6397.

[47] S. Sheik Mansoor, K. Aswin, K. Logaiya, S.P.N. Sudhan, J. Saudi Chem. Soc., 2016, 20, 138-150.

[48] (a) M. Kooti, M. Karimi, E. Nasiri, J. Nanopart. Res., 2018, 20, Art. No. 16; (b) Z. Arzehgar, S. Sajjadifar, H. Arandiyan, Asian J. Green Chem., 2019, 3, 43-52.

[49] S. Ameli, A. Davoodnia, M. Pordel, Org. Prep. Proced. Int., 2016, 48, 328336.

[50] M. Fattahi, A. Davoodnia, M. Pordel, Russ. J. Gen. Chem., 2017, 87, 863-867.

[51] F. Tajfirooz, A. Davoodnia, M. Pordel, M. Ebrahimi, A. Khojastehnezhad, Appl. Organometal. Chem., 2018, 32, Art. No. e3930.

[52] A. Nakhaei, A. Davoodnia, S. Yadegarian, Iran. Chem. Commun., 2018, 6, 334-345.

[53] E. Teymooria, A. Davoodnia, A. Khojastehnezhad, N. Hosseininasab, Iran. Chem. Commun., 2019, 7, 271-282. [54] (a) A.N. Egorochkin, O.V. Kuznetsova, N.M. Khamaletdinova, L.G. Domratcheva-Lvova, Inorganica Chim. Acta, 2018, 471, 148-158; (b) S. 
Sajjadifar, Chemical Methodologies, 2017, 1, 1-11.

[55] H. Anane, S.E. Houssame, A.E. Guerraze, A. Guermoune, A. Boutalib, A. Jarid, I. Nebot-Gil, F. Tomás, Cent. Eur. J. Chem. , 2008, 6, 400-403.

[56] M.H. Fekri, A. Omrani, S. Jamehbozorgi, M. Razavi mehr, Advanced Journal of Chemistry-Section A, 2019, 2, 14-20.
[57] H. Szatylowicz, A. Jezuita, T. Siodła, K.S. Varaksin, M.A. Domanski, K. Ejsmont, T.M. Krygowski, ACS Omega, 2017, 2, 7163-7171.

[58] R. Ghiasi, A.Zamani, J. Chin. Chem. Soc., 2017, 64, 1340-1346.

[59] R. Ghiasi, H. Pasdar, S. Fereidoni, Russian J. Inorg. Chem., 2016, 61, 327333.

[60] R. Ghiasi, A. Heydarbeighi, Russian J. Inorg. Chem., 2016, 61, 985-992.

How to cite this manuscript: Amir Samimi, Soroush Zarinabadi, Amir Hossein Shahbazi Kotanaei, Alireza Azimi, Masoumeh Mirzaei. "Use of data mining in the corrosion classification of pipelines in catalytic reforming units (CRU)". Eurasian Chemical Communications, 2019, 571-581. 